\title{
TREINAMENTO FUNCIONAL: UM ESTUDO BIBLIOGRÁFICO SOBRE OS CONCEITOS E APLICAÇÕES
}

\section{Functional training: a bibliographical study about the concepts and applications}

\author{
Diogo Alves de Oliveira'; André Luiz Viard Walsh-Monteiro ${ }^{2, ;}$ Cláudio Joaquim Borba-Pinheiro ${ }^{1,2,3}$ \\ ${ }^{1}$ Universidade do Estado do Pará (UEPA) Campus XIII de Tucuruí. \\ ${ }^{2}$ Instituto Federal do Pará (IFPA) Campus de Tucuruí. \\ ${ }^{3}$ Universidade Federal do Estado do Rio de Janeiro (UNIRIO). Programa de Pós graduação \\ Stricto Sensu em Enfermagem e Biociências (PPGEnfBio).
}

\begin{abstract}
Resumo: O estudo teve como objetivo analisar os conceitos e aplicações do Treinamento Funcional (TF) por diferentes autores. O método utilizado foi de revisão sistemática da literatura nas bases de dados Google acadêmico e portal de periódicos "CAPES", além de bibliotecas públicas. Foram encontradas 26 referências sendo 22 artigos e quatro livros. Com isso, foi realizada uma descrição dos princípios do TF sistematizando suas aplicações. A análise bibliográfica possibilitou verificar que a aplicação do TF tem priorizado três pontos. O primeiro, voltado para a reabilitação das capacidades funcionais. O segundo, como aprimoramento dos movimentos esportivos. E finalmente, o terceiro, voltada para o equilíbrio funcional, onde se busca uma maior autonomia e qualidade de vida. Assim, as aplicações do TF têm mostrado resultados satisfatórios nas três vertentes observadas, o que permite recomendar este tipo de treinamento como forma de preparação física de atletas e não atletas.

Palavras-chave: Atividade Física, Treinamento Funcional, Desempenho Físico.
\end{abstract}

Abstract: The study had as objective verifies the concepts and the systematic application of Functional Training (FT) for different authors. The methodology of systematic revision of the literature in bases for research: Academic Google, gate of journals "CAPES" and public libraries were used. It was found 26 references, being: 22 articles and four books. In addition, a description of the beginnings of the FT was accomplished systematizing your applications. The bibliographical analysis made possible to verify that the application of the FT has been prioritizing three points, the first, to the rehabilitation of the functional capacities. The second was for improvement of sports movements. Finally, the third that is returned for the functional balance looking for more autonomy and quality of life. The applications of the FT have been showing satisfactory results in the three points observed that allows to recommend the training in physical preparation of the athletes' and non-athletes.

Keywords: Physical Activity, Functional Training, Physical Performance.

\section{INTRODUÇÃO}

O TF tem como base os movimentos integrados e multiarticulares de estabilização, aceleração e desaceleração, com objetivos de desenvolver o movimento, a força e eficiência neuromuscular, para isso sugere movimentos que imitam situações naturais e de posições que poderiam ocorrer em situações reais da vida cotidiana ou competições esportivas, que podem ser ajustadas ao longo do chamado treinamento cognitivo $(1,2)$.

A essência do TF está baseada na melhoria dos aspectos neurológicos que afetam a capacidade funcional do corpo humano, através de exercícios que desafiam os diversos componentes do sistema nervoso e, por isso, estimulam sua adaptação. Isso re- sulta em uma melhoria das principais qualidades físicas utilizadas tanto nas atividades do dia-a-dia como nos gestos esportivos (3).

Os estudos (4-6) demonstram que TF tem obtido bons resultados na melhoria das capacidades funcionais voltados para a reabilitação, desempenho esportivo e qualidade de vida, respectivamente, de pessoas que buscam esse tipo de treinamento.

Com a posse dos conceitos e aplicações do TF pode-se trabalhar movimentos que se assemelham as atividades especificas, tanto do cotidiano como para uma modalidade esportiva, com a intenção de transferir os aprimoramentos dos exercícios ao objetivo proposto. Com isso, este trabalho poderá ser utilizado como uma metodologia alternativa de treinamento, o que pode justificar a sua importância. 
Desta forma, O estudo teve como objetivo analisar os conceitos e aplicações do Treinamento Funcional (TF) por diferentes autores.

\section{METODOLOGIA}

Para o presente estudo sobre os conceitos e aplicações do TF realizou-se uma revisão sistemática na literatura, utilizaram-se as palavras treinamento físico, treinamento funcional, desempenho físico e propriocepção como palavras-chave na busca de artigos nas bases do portal de periódicos da CAPES e Google Acadêmico, além do acervo da biblioteca UEPA/Campus XIII, a fim de incluir alguns livros para fornecer subsídios a realização desta revisão.

A pesquisa teve como critério de inclusão os artigos que utilizaram o Treinamento Funcional com intervenção prática de cinco a 24 semanas, com ou sem grupo controle e artigos de revisão da literatura, o que resultou em 22 artigos referentes aos princípios e fundamentos do treinamento e quatro livros, como mostra a Figura 1.

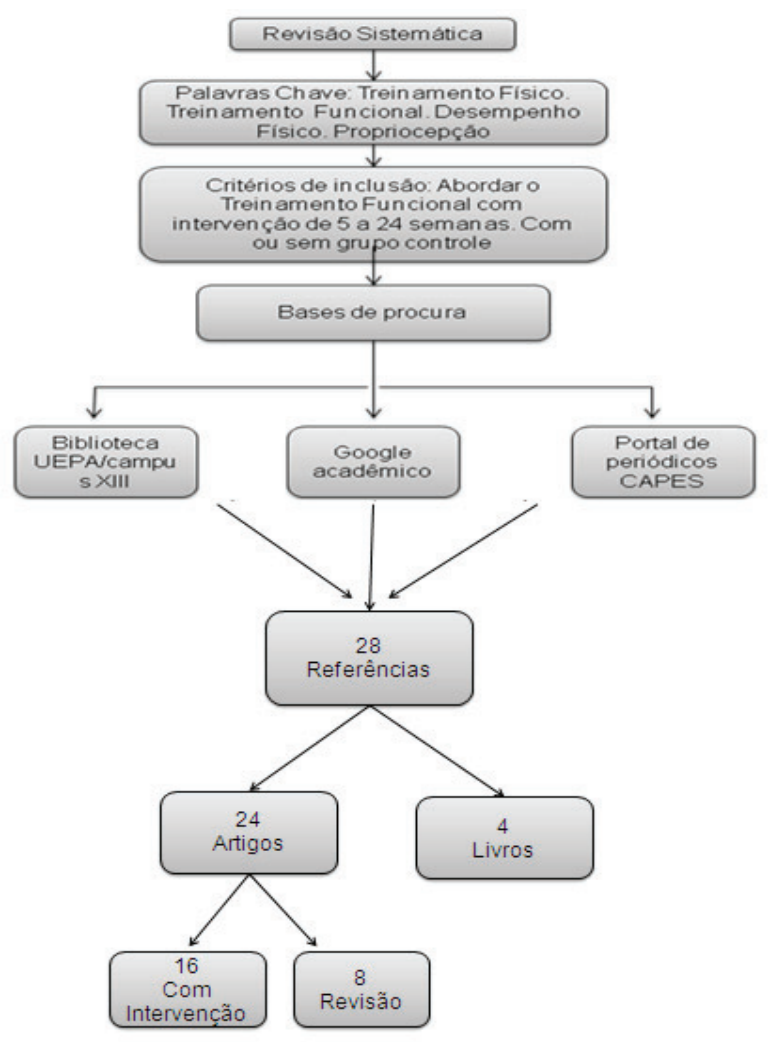

Figura 1. Revisão sistemática da literatura.

\section{DESENVOLVIMENTO}

\subsection{PRINCÍPIOS CIENTÍFICOS DO TREINAMENTO FÌSICO}

Partindo dos princípios do treinamento físico e das bases conceituais e de aplicação do Treinamento Funcional é possível estruturar um planejamento com uma metodologia que possibilite um aprimoramento das capacidades e habilidades motoras.

Assim, de acordo com as considerações de Tubino ${ }^{(7)}$, Dantas ${ }^{\left({ }^{(8)}\right.}$ e Costa ${ }^{(9)}$ o treinamento físico deve respeitar oito princípios metodológicos, quais sejam: da individualidade biológica, adaptação, sobrecarga, continuidade, interdependência volumeintensidade, especificidade, variabilidade e o principio da saúde:

- Individualidade biológica - Explica a variabilidade entre elementos da mesma espécie, fazendo com que não existam indivíduos iguais entre si, considerando as características físicas e psíquicas para os processos de condicionamento físico;

- Adaptação - Intimamente ligado ao stress, a qual a estrutura física é submetida levando a homeostase, isto é, a busca do equilíbrio do organismo humano considerando como estimulo, dentre outros: o exercício físico e as emoções para uma resposta e posteriormente uma adaptação;

- Sobrecarga - É uma adaptação do organismo com o propósito de superar um stress (estímulo) submetido anteriormente;

- Continuidade - É a não interrupção das condicionantes de preparação física para que se atinja a adaptação do organismo;

- Interdependência Volume-Intensidade - Ligado ao principio da sobrecarga, já que o volume e intensidade das cargas de trabalho e o processo de adaptação melhoram o desempenho do individuo;

- Especificidade - É o aprimoramento da habilidade técnica para a execução de movimentos quanto possíveis, durante o treinamento, visando a aquisição e reforço dos engramas (memória em mente) requeridos pela especificidade do esporte;

- Variabilidade - É o mais completo possível, baseado no treinamento total ou global, utiliza-se das mais variadas formas de treinamento, quanto maior for a variabilidade de estímulos, maiores serão as possibilidades de atingir melhores resultados; 
- Princípio da Saúde - Engloba outros setores que estão relacionados a uma melhor adequação das necessidades do individuo que busca uma atividade física, incluindo uma equipe multidisciplinar como apoio.

\subsection{PRINCÍPIOS DO TREINAMENTO FUNCIONAL}

Tendo por base o Treinamento Físico, Campos e Coraucci-Neto ${ }^{(3)}$ destacam oito princípios básicos do TF que sustentam sua aplicabilidade, tais como:

- Individualidade biológica - É o primeiro passo para um programa coerente. Um grupo de pessoas pode até ser homogênea com relação à idade, estatura etc., porém continuará sendo heterogênea em muitos outros aspectos, e, isso determina que o programa de exercício deve ser adequado a individualidade, de acordo com sua atividade funcional.

- Especificidade do Treinamento - este princípio tem relação com o princípio da individualidade biológica, as adaptações que o corpo sofre são especificas das atividades as quais são submetidas, suas contrações, velocidade e ângulo de execução, amplitude e sinergia entre os músculos, a postura e os sistemas energéticos, todas devem refletir a ação da atividade do atleta ou não atleta.

- Preparação de músculos intrínsecos - tem contribuição para a estabilização articular com objetivo de fortalecimento destas musculaturas para promover a estabilidade estática e dinâmica das articulações.

- Variação - a vida sedentária provoca redução na variedade dos movimentos do individuo, o que diminui a propriocepção. Dessa forma, quanto maior a variedade de estímulos, maiores serão as adequações de condicionamento.

- Equilíbrio muscular - exercícios que exigem equilíbrio estimulam o sistema de controle motor e favorecer ganho de força muscular, melhoria dos mecanismos proprioceptivos, diminuição dos desequilíbrios musculares causadores de desvios posturais e uma maior sinergia entre os músculos durante um movimento;

- Cadeias cinéticas - a) Fechadas, onde os segmentos distais encontram-se fixos ou com considerável resistência, como os exercícios com os pés no chão, como por exemplo, os exercícios de agachamento. b) Abertas, são quando os segmentos distais se encontram livres no espaço, como exemplo a extensão de joelho.

- Progressões - os exercícios podem progredir a partir da velocidade, de baixa para alta; da postura estática para a dinâmica; na resistência empregada baixa para alta; nos movimentos com equilíbrio para os sem equilíbrio; utilização da visão para a não utilização; movimentos bilaterais para unilaterais; movimentos simples para os complexos, de um plano para vários planos.

- Estimulação dos proprioceptores - a realização de exercícios com os olhos fechados estimula a ativação dos proprioceptores situados no sistema musculoesquelético e os receptores táteis.

\subsection{CONCEITUAÇÃO DO TREINAMENTO FUNCIONAL}

De acordo com os princípios supracitados o TF é conceituado como o conjunto de exercícios com movimentos que imitam situações reais, ou seja, que podem ocorrer nas atividades da vida diária. Partindo de exercícios de estabilização e fortalecimento da musculatura que sustenta e estabiliza a coluna vertebral em cadeia com os membros, conhecido como musculatura do núcleo "CORE" $(1,2,10)$.

Para Campos e Coraucci Neto ${ }^{(3)}$ a essência do TF está baseada na melhoria dos aspectos neurológicos que afetam a capacidade funcional, através de exercícios que desafiam os diversos componentes do sistema nervoso central e periférico em seus processos contínuos de feedback e, por isso, estimulam sua adaptação. Isso pode resultar em uma melhoria das capacidades e habilidades físicas utilizadas tanto nas atividades do dia-a-dia como nos gestos esportivos.

O TF tem como base os exercícios contínuos que envolvem o equilíbrio e a propriocepção, realizados no solo utilizando o peso corporal, com movimentos integrados, ou seja, combinações de movimentos ${ }^{(11)}$.

\subsection{CONSIDERAÇÕES PARA O PLANEJAMENTO DE UM PROGRAMA DE TREINAMENTO FUNCIONAL. \\ O TF pode ser aplicado para diferentes indiví- duos, o que diferencia é o grau de potência de um}


para o outro. Os exercícios do TF devem enfatizar os movimentos multiarticulares, onde os músculos trabalham em grupos coordenados. Eles também devem ser dinâmicos o suficiente para ativar os reflexos que melhoram a estabilidade do sistema com exigências de soluções hábeis, semelhantes aos problemas colocados pelas atividades atleticas ou da vida diária ${ }^{(11)}$.

Outro fator de grande importância para um programa de TF é a propriocepção, que é o senso de consciência corporal, sendo um importante componente para a estabilidade articular, envolvendo estruturas proprioceptivas como os receptores articulares de Ruffini e Pacini, receptores musculares como o Fuso muscular e os localizados nos tendões como os órgãos tendinosos de Golgi, além do Sistema vestibular com informações de movimentos lineares e angulares ${ }^{(3)}$. Para que esses mecanismos possam ser ativados pode-se iniciar um treinamento, tendo como ponto de partida os músculos do "CORE", mostrados na Tabela 1.

TABELA 1. Musculatura do núcleo (CORE) responsável pela estabilização da coluna vertebral.

\begin{tabular}{|c|c|}
\hline Estabilizadores da coluna lombar & Ação primária \\
\hline Reto abdominal & Flexão da coluna vertebral \\
\hline Obliquos & Rotação da coluna \\
\hline Multifidos & Estabilização segmentar vertebral \\
\hline Quadrado lombar & Inclinação lateral da coluna \\
\hline Paravertebrais & Extensão da coluna vertebral \\
\hline
\end{tabular}

Fonte: Norris (12) adaptado pelos autores.

\subsection{CAPACIDADES E HABILIDADES MOTORAS}

Para que o planejamento possibilite uma meIhora deve-se considerar o desenvolvimento das capacidades e habilidade motoras como: força, flexibilidade, equilíbrio, resistência, lateralidade, potência e agilidade ${ }^{(3)}$. Com isso, cabe considerar o conceito destas:

- Força - É a capacidade física imprescindível para a manutenção ou aprimoramento da capacidade funcional do corpo humano;

- Flexibilidade - É a habilidade para mover uma articulação através de uma amplitude de movimento normal sem estresse excessivo para a unidade, envolvendo a mobilidade articular e a elasticidade muscular. É importante ressaltar as variáveis que influenciam na flexibilidade como a hora do dia, temperatura do ambiente, sexo e idade;

- Equilíbrio - influencia na qualidade e controle dos movimentos de músculos estabilizadores (estabilizam uma articulação aproximando as superfícies articulares) e mobilizadores (responsáveis pelos movimentos articulares).

- Resistência cardiovascular e muscular - Aprimorados com o treinamento, retarda o aparecimento da fadiga muscular e aumenta o rendimento do sistema aeróbico e anaeróbico, vitais para manutenção ou melhoria das capacidades funcionais;

- Lateralidade - O ser humano tem dois hemisférios, direito e esquerdo, dos quais um será o dominante. Dessa forma, os exercícios unilaterais são benéficos para a manutenção das agilidades motoras, os bilaterais e simétricos são indicados para indivíduos iniciantes e só depois progredir para unilaterais e assimétricos;

- Potência - É a habilidade de utilizar a força (não necessariamente a força máxima) aliada à velocidade;

- Agilidade - É a habilidade de mudar a posição e/ou sentido do corpo sem perda de desempenho.

\subsection{EXERCÍCIOS PLIOMÉTRICOS}

A pliometria é outro termo bastante utilizado no TF, teve bastante popularidade nos anos $60 \mathrm{e}$ 70. Os exercícios pliométricos são definidos como aqueles que ativam o ciclo excêntrico-concêntrico, com aceleração e desaceleração dos músculos esqueléticos, provocando sua potenciação elástica, mecânica e reflexa ${ }^{(13,14)}$. Como exemplo de exercícios pliométricos pode-se citar os saltos verticais, como ilustra a Figura 2:

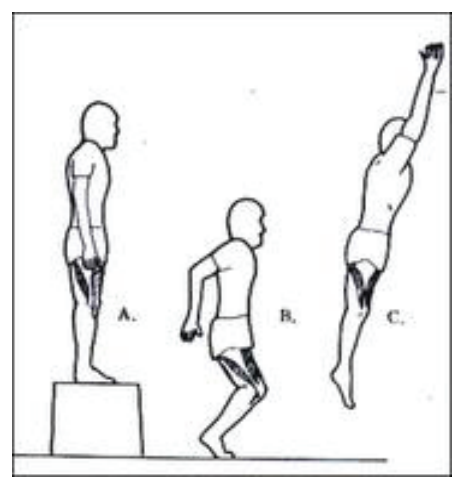

Figura 2: Exercício pliométrico. Imagem pública do google image (http://www.google.com/imghp?hl=pt-BR), sem reservas de domínio. 
O treinamento pliométrico é um conjunto de exercícios que objetiva aumentar a capacidade do músculo em armazenar e reutilizar energia elástica e ainda, aumentar sua potencialização reflexa e mecânica, denominado também de ciclo alongamento-encurtamento ${ }^{(15)}$. Para Boff e Da Silva ${ }^{(16)}$ o treinamento pliométrico pode obter bons resultados para o salto vertical de atletas escolares.

Para Plisk ${ }^{(11)}$ as estrutudas dos membros inferiores são projetadas para uma melhor adaptação do sitema de alongamento e encurtamento devido a presenças de tendões muitas vezes mais longos que o ventre dos muscúlos, como por exemplo, os extensores distais como os músculos gastrocnêmio e o sóleo. Isso pode minimizar a massa de parte inferior da perna, reduzindo as necessidades de energia durante a locomoção.

\subsection{APLICAÇÕES DO TREINAMENTO FUNCIONAL}

A Tabela 2 apresenta estudos com intervenção do TF em um período de cinco a 24 semanas. Os estudos que apresentaram resultados efetivos para os objetivos propostos tiveram uma frequência semanal média de três vezes por semana, com exercícios que se assemelham aos movimentos de modalidades esportivas ou da vida diária, tendo como principais os que proporcionam a estabilização e mobilização do tronco como a flexão/extensão, os exercícios isométricos e pliométricos.

Tabela 2. Apresenta estudos sobre a aplicação do TF.

\begin{tabular}{|c|c|c|c|c|c|c|c|}
\hline Autores (ano) & Titulo & Objetivo & Amostra & Frequência/ duração & Exercícios & Material & Resultado \\
\hline Cosio-Lima et al. ${ }^{(1 / 1)}$ & \begin{tabular}{|l|} 
Efeitos dos \\
exercícios com bola \\
na estabilidade do \\
núcleo e no equilibrio \\
de mulheres
\end{tabular} & $\begin{array}{l}\text { Comparar os efeitos dos } \\
\text { exercícios com bola na } \\
\text { estabilidade do núcleo e no } \\
\text { equilíbrio em mulheres }\end{array}$ & $\begin{array}{l}30 \quad \text { mulheres } \\
\text { universitárias. Grupo } 1 \\
\mathrm{n}=15 \text { exercicios com } \\
\text { bola. Grupo } 2 \mathrm{n}=15 \mathrm{sem} \\
\text { bola. } \\
23 \text { anos de idade }\end{array}$ & $\begin{array}{l}5 \text { vezes por semana; } \\
\text { durante } 5 \text { semanas. }\end{array}$ & \begin{tabular}{|l|} 
Flexão de tronco. \\
Extensão de tronco. \\
(ambos com progressões gradativas)
\end{tabular} & $\begin{array}{l}\text { Bola Suiça. } \\
\text { Colchonete. }\end{array}$ & $\begin{array}{l}\text { O grupo } 1 \text { teve melhoras } \\
(p<0,05) \text { comparado com o } \\
\text { grupo 2, nas variáveis de } \\
\text { estabilidade do núcleo e } \\
\text { equilibrio postural. }\end{array}$ \\
\hline Michell et al. ${ }^{(18)}$ & \begin{tabular}{|l|}
\multicolumn{2}{|l|}{ Treinamento de } \\
equilíbrio funcional \\
com tornozelos \\
estáveis e instáveis.
\end{tabular} & $\begin{array}{l}\text { Examinar os efeitos do } \\
\text { treinamento de equilibrio } \\
\text { funcional com e sem o uso } \\
\text { de sandálias estabilizadoras } \\
\text { do tornozelo. }\end{array}$ & $\begin{array}{l}32 \text { indivíduos. } \\
16 \text { com instabilidade do } \\
\text { tornozelo. } \\
16 \text { sem histórico de } \\
\text { lesão no tornozelo. }\end{array}$ & $\begin{array}{l}3 \text { vezes por semanas } \\
\text { durante } 8 \text { semanas. }\end{array}$ & $\begin{array}{l}\text { Alongamento do tendão calcâneo/Flexão } \\
\text { plantar/Caminhada com elevação do } \\
\text { joelho/Deslocamentolateral/Agachamento e } \\
\text { exercícios de Arranque. }\end{array}$ & $\begin{array}{l}\text { Sandálias com } \\
\text { solado de } \\
\text { borracha com } \\
\text { meia esfera fixa } \\
\text { no centro. }\end{array}$ & \\
\hline Corrêa et al. ${ }^{(19)}$ & \begin{tabular}{|l|} 
Efeito do treinamento \\
muscular periférico \\
na capacidade \\
funcional e qualidade \\
de vida nos \\
pacientes em \\
hemodiálise
\end{tabular} & $\begin{array}{l}\text { Avaliar os } \text { efeitos do } \\
\text { Treinamento } \text { Muscular } \\
\text { Periférico (TMP) e r na } \\
\text { qualidade de vida de } \\
\text { pacientes em hemodiálise. }\end{array}$ & $\begin{array}{l}7 \text { voluntários com idade } \\
\text { entre } 29 \text { e } 84 \text {. }\end{array}$ & $\begin{array}{l}2 \text { vezes por semana } \\
\text { durante } 5 \text { meses. }\end{array}$ & $\begin{array}{l}\text { Foram trabalhados todos os grupamentos } \\
\text { musculares dos membros inferiores (MI), } \\
\text { além dos abdominais e glúteos com } \\
\text { exercícios isométricos, isotônicos e livres de } \\
\text { carga. }\end{array}$ & $\begin{array}{l}\text { Equipamentos de } \\
\text { exercícios } \\
\text { resistidos. }\end{array}$ & $\begin{array}{l}\text { Houve aumento estatístico } \\
(p<0,05) \text { para a força de Ml. } \\
\text { Além das funções limite por } \\
\text { aspecto físico e vitalidade da } \\
\text { QV. }\end{array}$ \\
\hline Thompson at al. ${ }^{(20)}$ & $\begin{array}{|lr|}\text { Treinamento } & \\
\text { Funcional para } & 0 \\
\text { desempenho } & \text { de } \\
\text { idosos praticantes } & \text { de } \\
\text { golfe. }\end{array}$ & $\begin{array}{l}\text { Determinar os efeitos de um } \\
\text { programa progressivo de } \\
\text { Treinamento funcional } \\
\text { sobre o desempenho de } \\
\text { velocidade de balaço de } \\
\text { idosos golfistas. }\end{array}$ & $\begin{array}{l}18 \text { golfistas do sexo } \\
\text { masculino com idade de } \\
60 \text { a } 80 \text { anos. } \\
\text { Grupo de exercícios } \\
\mathrm{n}=11 . \\
\text { Grupo controle } \mathrm{n}=7\end{array}$ & $\begin{array}{l}3 \text { vezes por semana } \\
\text { durante } 8 \text { semanas; }\end{array}$ & $\begin{array}{l}\text { Exercícios de flexão. } \\
\text { Exercícios de estabilidade do núcleo. } \\
\text { Exercícios de equilibrio. } \\
\text { Exercícios de resistência. } \\
\text { Exercícios de alongamento. }\end{array}$ & $\begin{array}{l}\text { Bola Suíça. } \\
\text { Bola medicinal. } \\
\text { Faixa elástica. }\end{array}$ & $\begin{array}{l}\text { O grupo exercícios obteve } \\
\text { uma melhora } 4,9 \% \text { na } \\
\text { velocidade do balanço, } \\
\text { enquanto o grupo controle } \\
\text { houve uma diminuiçãa. }\end{array}$ \\
\hline Oliveira et al. ${ }^{(21)}$ & $\begin{array}{|lr|}0 & \text { treinamento } \\
\text { funcional ra ra } & \text { na } \\
\text { reeducação funcional } \\
\text { Após reconstrução } \\
\text { de ligamento cruzado } \\
\text { anterior. }\end{array}$ & $\begin{array}{l}\text { Este trabalho tem como } \\
\text { desígnio aprimorar a } \\
\text { capacidade funcional após } \\
\text { reconstrução de Ligamento } \\
\text { Cruzado Anterior do joelho } \\
\text { por meio do treinamento } \\
\text { funcional }\end{array}$ & $\begin{array}{l}\text { Foram } \\
\text { avaliados } 10 \text { pacientes } \\
\text { com faixa etária de } 22 \text { a } \\
33 \text { anos, submetidos à } \\
\text { reconstrução de LCA do } \\
\text { joelho. }\end{array}$ & $\begin{array}{l}8 \text { semanas. } \\
\text { Freqüência por semana } \\
\text { não relatadas. }\end{array}$ & $\begin{array}{l}1^{\text {a }} \text { fase: aumento de amplitude de movimento } \\
\text { Flexão/Extensão e exercícios isométricos. } \\
2^{\circ} \text { fase: fortalecimento muscular com cadeia } \\
\text { cinética fechada e treinamento funcional com } \\
\text { exercícios estáticos e dinâmicos. }\end{array}$ & $\begin{array}{l}\text { "balance disc", } \\
\text { bola suíça, } \\
\text { prancha de } \\
\text { equilibrio e cama } \\
\text { elástica }\end{array}$ & $\begin{array}{l}\text { Houve melhora na postura } \\
\text { geral, no equilibrio dinâmico e } \\
\text { estático, uma maior } \\
\text { estabilidade da coluna } \\
\text { vertebral, e ainda, melhora da } \\
\text { sinestesia. r r } \\
\text { r }\end{array}$ \\
\hline Leal et al. ${ }^{(22)}$. & \begin{tabular}{|l|} 
Efeitos do \\
treinamento funcional \\
na autonomia, \\
equilibrio e qualidade \\
de vida de idosas.
\end{tabular} & 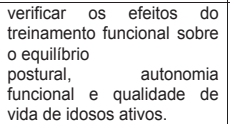 & $\begin{array}{l}76 \text { idosas. } \\
\text { Grupo treinamento } \\
\text { funcional }(n=42) \text {. } \\
\text { Grupo controle }(n=28) . \\
\text { Média de idade: } 66 \\
\text { anos. }\end{array}$ & $\begin{array}{l}\begin{array}{l}\text { 2xsemana, durante } 12 \\
\text { semanas. }\end{array} \\
\end{array}$ & $\begin{array}{l}\text { Exercícios de equilíbrio. } \\
\text { Exercíios de treinamento funcional resistido. } \\
\text { Exercícios de alongamento. } \\
\text { Ambos utilizando progressões de carga e } \\
\text { repetições. }\end{array}$ & Não descritos. & $\begin{array}{l}\text { O grupo treinamento funcional } \\
\text { teve melhora }(p<0,05) \text { nas três } \\
\text { variáveis analisadas, quando } \\
\text { comparados ao grupo } \\
\text { controle. }\end{array}$ \\
\hline Lustosa et al. ${ }^{(6)}$ & $\begin{array}{|lr|}\text { Efeito de } & \text { um } \\
\text { programa } & \text { de } \\
\text { treinamento funcional } \\
\text { no equilibrio postural } \\
\text { de idosas ra da } \\
\text { comunidade }\end{array}$ & $\begin{array}{l}\text { Verificar } \\
\text { o efeito de um programa de } \\
\text { dois meses } \\
\text { de exercícios funcionais em } \\
\text { um grupo } \\
\text { de idosas da comunidade } \\
\text { nas atividades instrumentais } \\
\text { de } \\
\text { vida diária e no equilibrio } \\
\text { unipodálico }\end{array}$ & $\begin{array}{l}7 \text { idosas da } \\
\text { comunidade, } \\
\text { sedentárias, sem } \\
\text { distinção } \\
\text { de raça e/ou classe } \\
\text { social. }\end{array}$ & $\begin{array}{|ll|}\text { 3xsemana } & \text { durante } 8 \\
\text { semanas. } & \text { Totalizando } \\
24 \text { sessões. } & \end{array}$ & $\begin{array}{l}\text { Exercícios relacionados às tarefas } \\
\text { executadas no dia-dia das participantes } \\
\text { como: caminha de 10 minutos para } \\
\text { aquecimento, exercícios de marcha em } \\
\text { flexão plantar, dorsiflexão. } \\
\text { Todos os exercícios tiveram progressões } \\
\text { com utilização de cargas. }\end{array}$ & $\begin{array}{l}\text { Cones. } \\
\text { Bambolê. } \\
\text { Colchonete } \\
\text { Bolas. } \\
\text { Bastões }\end{array}$ & $\begin{array}{l}\text { O resultado não apresentou } \\
\text { diferença ( } p<0,05 \text { ) para o } \\
\text { equilibrio unipodálico em } \\
\text { ambos os membros inferiores, } \\
\text { porém, houve melhora } \\
\text { significativa ( } p=0,042) \text { para a } \\
\text { capacidade de realizar as } \\
\text { AlVD. }\end{array}$ \\
\hline Nunciato et al. ${ }^{(4)}$. & \begin{tabular}{|lr|}
\multicolumn{2}{|l|}{ Treinamento de força } \\
e r r & treinamento \\
funcional & em \\
adolescente & lesado \\
medular & \\
\end{tabular} & $\begin{array}{l}\text { Analisar a influência do } \\
\text { treinamento de força } \\
\text { associado ao treinamento } \\
\text { especifico funcional, sobre a } \\
\text { independência funcional de } \\
\text { uma paciente com lesão }\end{array}$ & $\begin{array}{l}1 \text { voluntario com lesão } \\
\text { medular do sexo } \\
\text { masculino, com } 12 \text { anos } \\
\text { de idade. }\end{array}$ & $\begin{array}{|lll|}\begin{array}{l}\text { 3xsemana } \\
\text { semanas. }\end{array} & \text { durante } 8 \\
\end{array}$ & $\begin{array}{l}\text { Exercícios de fortalecimento dos músculos } \\
\text { flexores e extensores do tronco: } 3 \text { séries; } 20 \\
\text { repet. para cada grupo muscular, com } \\
\text { utilização da bola feijão }(55 \times 80 \mathrm{~cm}) \text {, além de } \\
\text { exercícios de avanço, da cadeira de rodas } \\
\text { para o piso. }\end{array}$ & $\begin{array}{l}\text { Bola feijão. } \\
\text { Colchonete } \\
\text { Bola Suiça. }\end{array}$ & $\begin{array}{l}\text { Melhora funcional }(p<0,05) \text { na } \\
\text { força superior a } 15 \% \text { da } \\
\text { medida de independência } \\
\text { funcional, proporcionando uma } \\
\text { discreta melhora nas } \\
\text { qualidades de transferências. }\end{array}$ \\
\hline King et al. ${ }^{(23)}$ & \begin{tabular}{|l} 
Confiabilidade r e \\
capacidade re de \\
resposta \\
do desempenho \\
fisico \\
no contexto do \\
Treinamento \\
Funcional
\end{tabular} & $\begin{array}{l}\text { Verificar as medidas de } \\
\text { resistência, força r e } \\
\text { flexibilidade, } \\
\text { intervenção de treinamento } \\
\text { funcional destinador a } \\
\text { melhorar as AVD de } \\
\text { pessoas idosas. }\end{array}$ & $\begin{array}{l}37 \text { idosos com idade } \\
\text { média de } 70 \text { anos. } \\
\text { Grupo intervenção } \\
(n=18) \text {. } \\
\text { Grupo controle }(n=19) . \\
78 \% \text { do sexo feminino. }\end{array}$ & $\begin{array}{l}\text { 3xsemana durante } 12 \\
\text { semanas }\end{array}$ & $\begin{array}{l}\text { Circuito de caminhada de } 15 \text { minutos. } \\
\text { Sentar e levantar da cadeira. } \\
\text { Exercícios de flexão e dorsiflexao. } \\
\text { Exercícios de equilíbrio estático e dinâmico. } \\
\text { Flexão e extensão de tronco. }\end{array}$ & $\begin{array}{l}\text { Saco de areia e } \\
\text { halteres } \\
\text { Cadeira, porta, } \\
\text { tapete, paredes e } \\
\text { degraus de } \\
\text { escada. }\end{array}$ & $\begin{array}{l}\text { Não houve diferença }(p<0,05) \\
\text { para a caminhada entre os } \\
\text { grupos, já as demais variáveis } \\
\text { obtiveram diferenças ( } p<0,05) \\
\text { quando comparadas entre os } \\
\text { grupos. }\end{array}$ \\
\hline Yaggie e Campbell $^{(24)}$ & $\begin{array}{|lr|}\text { Efeitos } & \text { do } \\
\text { treinamento } & \text { de } \\
\text { balanço } & \text { sobre } \\
\text { habilidades } & \\
\text { selecionadas } & \\
\end{array}$ & $\begin{array}{l}\text { Determinar a influência } \\
\text { de um protocolo de } \\
\text { treinamento de equilibrio, } \\
\text { utilizando o BOSU, em } \\
\begin{array}{llr}\text { postura dinâmica } & \text { e } \\
\text { desempenho funcional em } \\
\text { indivíduos saudáveis. }\end{array} \\
\end{array}$ & $\begin{array}{l}36 \text { voluntários. } \\
\text { Grupo experimental } \\
(n=17) . \quad \text { Gontrole }(n=19) \\
\text { Grupo }\end{array}$ & $\begin{array}{l}\text { Período do experimento } \\
\text { foi de } 4 \text { semanas, } 3 \times x \\
\text { semana. }\end{array}$ & $\begin{array}{l}\text { Exercícios utilizando o BOSU. } \\
\text { Giros laterais de cabeça. } \\
\text { Movimento de cabeça com os olhos } \\
\text { vendados. } \\
\text { Movimentos de tronco. }\end{array}$ & $\begin{array}{l}\text { Bola Suíça. } \\
\text { Bola BOSU. }\end{array}$ & $\begin{array}{l}\text { Melhorou as capacidades } \\
\text { proprioceptivas. Porém, a } \\
\text { utilização do BOSU não } \\
\text { obteve melhoras no salto } \\
\text { vertical. }\end{array}$ \\
\hline
\end{tabular}




\begin{tabular}{|c|c|c|c|c|c|c|c|}
\hline Stanton et al. ${ }^{(5)}$ & $\begin{array}{l}\text { O efeito de curto } \\
\text { prazo de formação } \\
\text { na bola suiça sobre } \\
\text { estabilidade do core: } \\
\text { economia de corrida }\end{array}$ & 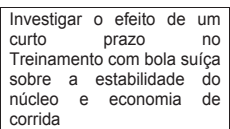 & \begin{tabular}{|l|}
18 jovens atletas do \\
sexo masculino. \\
Grupo experimental \\
$(n=8)$. \\
Grupo controle $(n=10)$.
\end{tabular} & \begin{tabular}{|lll}
$\begin{array}{l}2 \times s e m a n a \\
\text { semanas. }\end{array}$ & durante & 6 \\
\end{tabular} & $\begin{array}{l}\text { Exercício de salto vertical. } \\
\text { Rolamento lateral supinado. } \\
\text { Superman alternado. } \\
\text { Flexão de joelho. } \\
\text { Extensão de pernas. } \\
\text { Movimento de rotação de tronco. }\end{array}$ & $\begin{array}{l}\text { Bola Suiça. } \\
\text { Colchonete } \\
\text { Esteira } \\
\text { ergométrica. }\end{array}$ & $\begin{array}{l}\text { Houve melhora no grupo } \\
\text { experimental significativa } \\
(p<0,05) \text { na estabilide da } \\
\text { musculatura do CORE, além } \\
\text { de melhorias no desempenho } \\
\text { aeróbico específico. }\end{array}$ \\
\hline Myer et al. ${ }^{(23)}$ & \begin{tabular}{|lr} 
Efeitos & do \\
treinamento & \\
pliométrico r & contra \\
exercicios & de \\
estabilidades & \\
dinâmicas & no \\
equilibrio e força de & mulheres atletas \\
mulhes
\end{tabular} & 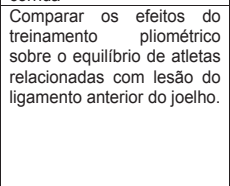 & $\begin{array}{l}19 \text { mulheres ativas, com } \\
\text { idade média de } 15,5 \\
\text { anos. } \\
\text { Grupo Plyo. }(n=8) \\
\text { Grupo Ball }(n=11) \text {. }\end{array}$ & $\begin{array}{l}3 \text { vezes por semanas } \\
\text { durante } 7 \text { semanas. }\end{array}$ & $\begin{array}{l}\text { Exercícios pliométricos: } \\
\text { Saltos. } \\
\text { Corrida com barreira. } \\
\text { Combinados com abdominais. } \\
\text { (entre outros). } \\
\text { Exercícios de estabilidade: } \\
\text { Exercícios simétricos. } \\
\text { Agachamento profundo. } \\
\text { Exercícios com BOSU e circuitos. }\end{array}$ & \begin{tabular}{|l} 
Step \\
Bola Suiça \\
Bola BOSU.
\end{tabular} & $\begin{array}{l}\text { Ambos os treinamento são } \\
\text { eficazes para melhorar o } \\
\text { desempenho funcional do } \\
\text { Ligamento Cruzado Anterior } \\
\text { do joelho em mulheres ativas. }\end{array}$ \\
\hline Paw et al. ${ }^{(26)}$ & $\begin{array}{l}\text { Efeitos do } \\
\text { treinamento resistido } \\
\text { e treinamento } \\
\text { funcional na } \\
\text { qualidade de vida de } \\
\text { idosos residentes em } \\
\text { casas de apoio. }\end{array}$ & 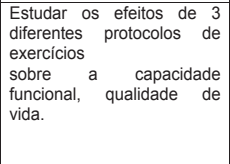 & \begin{tabular}{|l|}
173 idosos. \\
Grupo treinam. Resistido \\
$(\mathrm{n}=41) . \quad$ \\
Grupo treinam. \\
Funcional $(\mathrm{n}=48)$. \\
Grupo \\
Combinado $(\mathrm{n}=49)$ \\
Grupo controle $(35)$.
\end{tabular} & $\begin{array}{l}\text { 2xsemanas durante } 24 \\
\text { semanas. }\end{array}$ & $\begin{array}{l}\text { Exercícios resistidos e } \\
\text { Exercícios funcionais: } \\
\text { Caminhada. } \\
\text { Atividades rítmicas. } \\
\text { Arremesso de bola. } \\
\text { Levantar e sentar na cadeira. } \\
\text { Jogos cooperativos. } \\
\text { Alongamentos. }\end{array}$ & \begin{tabular}{|l|} 
Equipamentos de \\
musculação: \\
halteres \\
tornozeleiras de 1 \\
a $5 \mathrm{~kg}$.
\end{tabular} & $\begin{array}{l}\text { Ambos os protocolos de } \\
\text { obtiveram melhoras nas } \\
\text { variáveis estudas, porém, sem } \\
\text { diferença }(p<0,05) \text {. }\end{array}$ \\
\hline Utsch et al. (15) & \begin{tabular}{|lr} 
Influência & do \\
treinamento & \\
pliométrico em areia \\
e grama sobre a \\
potência r e \\
velocidade & em \\
jogadores de & futebol \\
juvenis &
\end{tabular} & $\begin{array}{l}\text { Analisar os efeitos de um } \\
\text { protocolo sistematizado de } \\
\text { treinamento pliométrico } \\
\text { realizado na grama e na } \\
\text { areia sobre as capacidades } \\
\text { físicas de força e } \\
\text { Velocidade de Corrida de } \\
\text { jogadores juvenis de } \\
\text { futebol. }\end{array}$ & 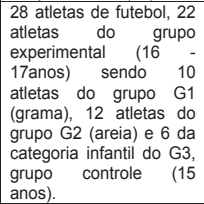 & \begin{tabular}{|l|}
8 semanas. \\
3xsemana nas primeiro \\
4 semanas. \\
2xsemana nas ultimas 4 \\
semanas.
\end{tabular} & $\begin{array}{l}\text { Exercícios de salto verticais e horizontais, } \\
\text { com e sem barreiras, e sprints de até } 25 \\
\text { metros: } 2 \text { séries, } 6 \text { exercícios, intervalos de } \\
\text { 1'30" entre séries e } 45^{\prime \prime} \text { entre exercícios, } \\
\text { exercícios de estabilização do tronco: } 2 \\
\text { séries, } 10 \text { repetiçōes de flexão/extensão do } \\
\text { tronco. }\end{array}$ & Não descrito. & $\begin{array}{l}\text { Os resultados sugerem que o } \\
\text { TF pliométrico na grama e na } \\
\text { areia podem ser utilizados } \\
\text { para a melhoria da potência } \\
\text { muscular dos membros } \\
\text { inferiores dos atletas }\end{array}$ \\
\hline Spennewyn ${ }^{(2 \pi)}$ & $\begin{array}{l}\text { Resultados de } \\
\text { exercicios resistidos } \\
\text { de forma livre contra } \\
\text { exercicios resistidos } \\
\text { em equipamentos de } \\
\text { forma fixa }\end{array}$ & $\begin{array}{l}\text { Comparar as medidas de } \\
\text { força } \\
e \text { de equilibrio entre } \\
\text { individuos usando forma } \\
\text { fixa ou de forma livre de } \\
\text { treinamento de resistência }\end{array}$ & $\begin{array}{l}30 \quad \text { voluntários } \\
\text { sedentários com idade } \\
\text { média de } 49 \text { anos. } \\
\text { Grupo livre }(n=10) \text {. } \\
\text { Grupo fixo }(n=10) \text {. } \\
\text { Grupo controle }(n=10) \text {. }\end{array}$ & $\begin{array}{l}\begin{array}{l}2 \times s e m a n a \\
\text { semanas. }\end{array} \\
\text { durante } 16 \\
\end{array}$ & $\begin{array}{l}\text { De } 8 \text { a } 12 \text { repetições para cada grupo } \\
\text { muscular em maquina fixa. } \\
8 \text { a } 12 \text { repetições para cada grupo muscular } \\
\text { de forma livre com mudança de posição (em } \\
\text { pé ou sentado). }\end{array}$ & \begin{tabular}{|l|} 
Leg-press. \\
Extensa/Flexora . \\
Tração. \\
Rosca. \\
Máquina de \\
abdominal. \\
Halteres. \\
\end{tabular} & $\begin{array}{l}\text { Os grupos de forma livre e fixa } \\
\text { obtiveram melhoras }(p<0,05) \text {. } \\
\text { No entanto o grupo livre teve } \\
\text { melhora de força de } 115 \% \text {, e } \\
\text { equilibrio de } 245 \% \\
\text { superiores ao Grupo forma } \\
\text { fixa. }\end{array}$ \\
\hline
\end{tabular}

A Tabela 2, apresentada o resultado de informações extraídas da literatura científica, que representam as vertentes no qual o método de treino tem sido utilizado. Desta forma, dentre outros estudos como os de Corrêa et al. ${ }^{(19)}$, Oliveira et al. ${ }^{(21)}$ e Nunciato et al. ${ }^{(4)}$ aproximam-se da vertente da reabilitação. Stanton et al. ${ }^{(5)}$ e Utsch et al. ${ }^{(15)}$ aproximam-se da vertente do aprimoramento desportivo. E finalmente, Lustosa et al. ${ }^{(6)}$ Corrêa et al. ${ }^{(19)}$ e Leal et al. ${ }^{(22)}$ da vertente qualidade de vida.

O estudo realizado por Oliveira et al. ${ }^{(21)}$ com 10 indivíduos de 22 a 33 anos, após cirurgia de reconstrução do ligamento cruzado anterior do joelho, com objetivo de aprimorar as capacidades funcionais através do TF. Os exercícios foram realizados de forma lenta com cinco a 10 repetições e duração de 25 segundos, sendo realizado o fortalecimento muscular em cadeia cinemática aberta na fase inicial e intermediária. Na fase final do treinamento, se utilizou exercícios de instabilidade estática e dinâmica em cadeia cinemática fechada, onde os materiais utilizados foram: "balance disc", bola suíça, prancha de equilíbrio e cama elástica. Os resultados apontaram um aumento na confiança e na capacidade funcional onde: dois pacientes afirmaram boa, quatro ótima e finalmente mais quatro afirmaram adquirir excelente capacidade funcional ${ }^{(21)}$. Após oito semanas, concluíram que houve melhora na postura geral, no equilíbrio dinâmico e estático, uma maior estabilidade da coluna vertebral, e ainda, melhora da consciência sinestésica (21).

Em outro estudo, que analisou os efeitos do treinamento de força associado ao funcional em um adolescente com lesão medular com exercícios de fortalecimento dos músculos flexores e extensores do tronco: três séries de 20 repetições para cada grupo muscular (reto abdominal, obliquo e paravertebrais), utilizando exercícios de flexão em decúbito ventral; extensão, em decúbito dorsal, com utilização de uma bola $(55 \times 80 \mathrm{~cm})$, além de exercícios de avanços, da cadeira de rodas para o piso. Após oito semanas, constatou-se uma melhora significativa na força e melhora superior a $15 \%$ da medida de autonomia funcional, proporcionando uma discreta melhora nas qualidades de transferências bem como em suas atividades funcionais ${ }^{(4)}$.

Para Stanton et al. ${ }^{(5)}$ que examinou os efeitos de seis semanas de treinamento com objetivo de estabilizar a coluna vertebral em 18 atletas de basquetebol divididos em dois grupos: o grupo experimental $(n=8)$ e o grupo controle $(n=10)$. No periodo de intervenção, tanto o grupo controle quanto o experimental, continuaram exercendo suas atividades de condicionamento esportivo periodiacamente duas vezes/semana. No TF utilizou-se a bola suíça e esteiras ergométricas. Após a avaliação, constatou-se que no grupo experimental hove uma melhora signi- 
ficativa $(p<0,05)$ na estabilide da musculatura do núcleo (CORE), medido pelo teste de Sahrmann com almofada de pressão inflável, além de melhorias no desempenho aeróbico específico da modalidade o que não ocorreu com o grupo controle ${ }^{(5)}$.

Em relação à preparação física de atletas, a discussão toma sentido quando os diferentes meios e métodos que constituem os elementos práticos da preparação desportiva são considerados, quando é necessário entender que quanto maior é o grau de correspondência entre os modelos utilizados (exercícios de treinamento) e a competição, maiores e mais eficazes serão os seus efeitos ${ }^{(28)}$. Dessa forma, no contexto atual do futebol, a forma de organização deve buscar o desempenho dos jogadores em curto período de tempo, e com isso, a preparação de futebolistas profissionais indica a necessidade de pesquisas envolvendo propostas de sistematização de treinamento para esta realidade ${ }^{(28)}$.

Utsch et al. ${ }^{(15)}$ ao analisarem os efeitos de um protocolo sistematizado de TF pliométrico realizado na grama e na areia sobre as capacidades físicas de força e velocidade da Corrida de 10, 20 e 30 metros em 28 jogadores juvenis de futebol, separados em três grupos; grupo grama ( $\mathrm{G} 1 \mathrm{n}=10)$; grupo areia ( $\mathrm{G} 2 \mathrm{n}=12$ ) e grupo controle ( $\mathrm{G} 3 \mathrm{n}=6$ ), com media de 16 anos, onde os grupos experimentais realizaram as atividades em um mesmo período e horário. Nas primeiras quatro semanas - foram realizadas três sessões/semana com exercícios de salto verticais e horizontais, com e sem barreiras, e sprints de até 25 metros, executando-se duas séries de seis exercícios, com intervalos de 1'30" entre séries e 45" entre exercícios, além de exercícios de estabilização do tronco com duas séries de 10 repetições na flexão/ extensão do tronco. Nas quatro últimas semanas o número de sessões foi reduzido para 2 sessões semanais ${ }^{(15)}$. Os resultados sugerem que o TF pliométrico na grama e na areia podem ser utilizados para a melhoria da potência muscular dos membros inferiores dos atletas.

Os estudos com objetivo de manter e/ou meIhorar a autonomia funcional e qualidade de vida em pessoas idosas vêm ganhando espaço na comunidade científica. Para Lustosa et al. ${ }^{(6)}$ que verificou os efeitos de um programa de dois meses de exercícios funcionais em um grupo de idosas com $71 \pm 8,1$ anos, avaliando o equilíbrio unipodálico e o impacto nas atividades instrumentais de vida diária (AIVD), tais como: capacidade de preparar uma refeição, realizar limpeza doméstica, subir escadas, caminhar, fazer compras e utilizar transporte coletivo. $O$ TF consistiu em exercícios relacionados às tarefas executadas no dia-dia das participantes, tais como: caminha de 10 minutos para aquecimento, exercícios de marcha em flexão plantar, dorsiflexão, dentre outros. Essas atividades tiveram progressão com a utilização de objetos nas mãos, como pequenos cones, além de circuito de exercícios. O resultado não apresentou diferença estatística $(p<0,05)$ para o equilíbrio estático unipodálico em ambos os membros inferiores, porém, houve melhora significativa $(p=0,042)$ para a capacidade de realizar as AIVD (6).

Em um estudo similar ao supracitado, Leal et al. ${ }^{(22)}$ analisou os efeitos de 12 semanas com intervenção de duas sessões/semana com duração de 50 minutos de TF sobre as variáveis de: equilíbrio postural, autonomia funcional e qualidade de vida em idosas com idades entre 60 e 67 anos, separadas em dois grupos: o grupo treinamento funcional (GTF; $n=42$ ) e o grupo controle (GC; $n=28$ ), sendo que este ultimo realizou durante o período de intervenção, atividades esporádicas de recreação e alongamento.

A Tabela 3 apresenta uma sequência de exercícios para treinamento funcional.

TABELA 3: Apresenta uma sequência de exercícios para TF

\begin{tabular}{|c|c|c|c|c|c|}
\hline \multirow{2}{*}{ Treinamentos } & \multirow[t]{2}{*}{ Exercícios } & \multicolumn{2}{|c|}{ Ciclo 1 (8 semanas) } & \multicolumn{2}{|c|}{ Ciclo 2 (8 semanas) } \\
\hline & & Carga & Repetições & Carga & Repetição \\
\hline \multirow[t]{3}{*}{ Equilibrio } & $\begin{array}{l}\text { Exercícios sem } \\
\text { estímulo visual }\end{array}$ & \multirow[t]{3}{*}{$\begin{array}{c}\text { Não } \\
\text { especificado }\end{array}$} & \multirow{3}{*}{$\begin{array}{c}15 \text { a } 20 \\
\text { segundos } \\
3 \text { a } 4 \\
\text { repetições }\end{array}$} & \multirow[t]{3}{*}{$\begin{array}{c}\text { Não } \\
\text { especificado }\end{array}$} & \multirow{3}{*}{$\begin{array}{c}15 \text { a } 20 \\
\text { segundos } \\
3 \text { a } 4 \\
\text { repetições }\end{array}$} \\
\hline & Exercícios com giros & & & & \\
\hline & $\begin{array}{c}\text { Exercícios } \\
\text { coordenados (uni e } \\
\text { bilaterais) }\end{array}$ & & & & \\
\hline \multirow[t]{8}{*}{ TF + Resistido } & $\begin{array}{c}\text { Agachamento livre com } \\
\text { halteres }\end{array}$ & \multirow{8}{*}{$55 \%$ - $1 \mathrm{RM}$} & \multirow{8}{*}{$\begin{array}{l}2 \text { séries de } 15 \\
\text { repetições }\end{array}$} & \multirow{8}{*}{$\begin{array}{c}60 \text { a } 70 \% \\
\text { 1RM }\end{array}$} & \multirow{8}{*}{$\begin{array}{c}2 \text { série de } 10 \\
\text { a } 12 \\
\text { repetições }\end{array}$} \\
\hline & Puxada por latíssimo & & & & \\
\hline & Abdominal & & & & \\
\hline & Supino horizontal & & & & \\
\hline & $\begin{array}{c}\text { Agachamento apoiado } \\
\text { na bola suíça }\end{array}$ & & & & \\
\hline & $\begin{array}{c}\text { Tríceps com faixa } \\
\text { elástica }\end{array}$ & & & & \\
\hline & $\begin{array}{c}\text { Panturrilha com peso } \\
\text { Livre }\end{array}$ & & & & \\
\hline & $\begin{array}{c}\text { Rosca direta com } \\
\text { halteres }\end{array}$ & & & & \\
\hline Alongamento & Não especificado & $\begin{array}{l}\text { Nivel sub } \text { máx } \\
\text { amplitude } \\
\text { articular. }\end{array}$ & $\begin{array}{c}1 \text { série de } 4 \\
\text { minutos }\end{array}$ & \begin{tabular}{|c} 
Nivel sub $_{\text {máx }}$ \\
amplitude \\
articular.
\end{tabular} & $\begin{array}{c}1 \text { série de } 4 \\
\text { minutos }\end{array}$ \\
\hline
\end{tabular}

Fonte: Leal et al. (22) adaptado pelos autores. 
Os resultados para o equilíbrio, qualidade de vida e autonomia funcional apresentaram uma melhora significativa $(p<0,05)$ quando comparado ao grupo controle ${ }^{(22)}$.

Outro estudo $^{(19)}$ (Tabela 2) com o objetivo de verificar efeitos do Treinamento Muscular Periférico e na qualidade de vida de pacientes em hemodiálise, com duas sessões semanais e um período de cinco meses constatou melhoras significativas $(p<0,05)$ nos MID e $E$, além de meIhorar a vitalidade e o limite por aspectos físicos relacionados à qualidade de vida. Em concordância disto, as propostas de treinamento funcional relacionados ao treinamento com pesos tem demonstrado eficiência para autonomia funcional e qualidade de vida em idosos ${ }^{(19,26,27)}$.

De outra forma, os estudos ${ }^{(4,6,23)}$ mostrados na Tabela 2 que utilizaram outros métodos como o circuito com multicomponente de exercícios também apresentaram resultados satisfatórios, especialmente, para as variáveis de força, equilíbrio e resistência, que estão relacionadas a autonomia e consequentemente as AVDs.

É importante ressaltar, que não é objetivo deste estudo, padronizar uma metodologia de aplicação do TF e nem sistematizar um único método de trabalho, e sim, agrupar de forma sistemática, metodologias desenvolvidas por diferentes autores, a fim de mostrar o valor de um planejamento voltado às especificidades funcionais de cada indivíduo.

Contudo, os resultados apresentados na literatura sugerem que o TF pode ser um programa de treinamento alternativo, tanto para adultos, atletas e idosos. Entretanto, mais estudos necessitam ser realizados com maior número de voluntários, com randomização de grupos, incluindo grupo de controle.

\section{CONSIDERAÇÕES FINAIS}

O TF tem por base o desenvolvimento da funcionalidade do corpo humano, trabalhando os movimentos que se assemelham com as atividades especificas, tanto do cotidiano como para uma modalidade esportiva. De acordo com a literatura, essa metodologia pode ser uma alternativa para treinamento para diferentes modalidades esportivas, bem como para o desenvolvimento de variáveis relacionadas à saúde.

Os estudos encontrados mostram que o TF tem priorizado três vertentes, quais sejam: 1- a reabilitação das capacidades funcionais, cujo, o objetivo é a reeducação de uma determinada função, 2- o aprimoramento dos movimentos esportivos, com o objetivo de potencializar a performance de uma determinada modalidade e finalmente 3- para desenvolver o equilíbrio funcional buscando uma maior autonomia e qualidade de vida. Assim, as aplicações do TF têm mostrado resultados satisfatórios nas três vertentes. Entretanto, ainda são poucos os estudos de intervenção com grupos de controle relacionados a este método de treinamento, o que convém recomendar mais estudos deste tipo de intervenção, a fim de consolidá-lo como forma de preparação física de atletas, também para reabilitação e qualidade de vida de não atletas.

\section{REFERÊNCIAS BIBLIOGRÁFICAS}

1- Elvar JRH, Ramón M, Chulvi I. Entrenamiento funcional: revisíon y replanteamentos. Revista Digital EFDeportes - Buenos Aires 2006;12(117). Disponível em: http://www.efdeportes.com.efd98/efunc.htm.

2- Elvar JRH, Chulvi I, Isidro $\mathrm{F}$ et al. El entrenamiento funcional y la inestabilidad en el fitness. Revista Digital EFDeportes - Buenos Aires, 2008;10(70). Disponível em: http://www.efdeportes.com/efd117/el-entrenamiento-funcional-y-la-inestabilidad-en-el-fitness.htm.

3- Campos MA, Coraucci Neto B. Treinamento funcional resistido: para melhoria da capacidade funcional e reabilitação de lesões musculoesqueléticas. Rio de Janeiro: Revinter, 2004.

4- Nunciato AC, Pastrelo D, Leite RD et al. Treinamento de força e treinamento funcional em adolescente lesado medular - relato de caso. ConScientiace 2009:8(2):28188. Disponível em: http://www4.uninove.br/ojs/index. php/saude/article/view/1644/1297.

5- Stanton R, Reaburn PR and Humphries B. The effect of short-term swiss ball training on core stability and running economy. J. Strength Conditioning Research, 2004;18(3):522-28. Disponível em: http://www.pnfchi. com/foto /literatura/1233837313.pdf. 
6- Lustosa LP, Oliveira LA, Santos LS et al. Efeito de um programa de treinamento funcional no equilíbrio postural de idosas da comunidade. Rev Fisioterapia e Pesquisa. 2010;17(2):153-6. Disponível em: http://www.revistasusp.sibi.usp.br/pdf/fpusp/v17n2/11.pdf.

7- Tubino MJG. Metodologia cientifica do treinamento desportivo. 11. ed. São Paulo: Ibrasa, 1984.

8- Dantas, EHM. A Prática da Preparação Física. 4. ed. Rio de Janeiro: Shape, 2003.

9- Costa MG. Ginástica Localizada. Rio de Janeiro: Sprint, 1996.

10- Chulvi I, Heredia JR, Colado JC. O treinamento físico na melhoria da saúde pessoal e desempenho atlético: Revista Digital EFDeportes - Buenos Aires, 2007;12(112). Disponível em: http://www.efdeportes.com/efd112/el-entrenamiento-fisico-ersonalizado.htm.

11- Plisk P. Functional Training. National Strength and Conditioning Association - session Hot Topic NSCA, Nevada, 2006. Disponível em: http://www.nsca-lift.org/HotTopic/download/Functional\%20Training\%20modified[1]. pdf.

12- Norris, C.M. Functional load abdominal training: part 1. J. Bodywork Movement Therapies 1999;3(3):150-158

13- Moura NA, Moura TFP. Princípios do treinamento em saltadores: implicações para o desenvolvimento da força muscular. In. I Congresso Sul-americano de treinadores de atletismo Anais.... Manaus, 2001. Disponível em: http://www.mmatletismo.com.br/My_Homepage_Files/Publica\%C3\%A7\%C3\%B5es\%20e\%20Estudos/ NSA\%20-\%20por.pdf.

14- Rossi LP, Brandalize M, Pacheco MT. Bases fisiológicas do treinamento pliométrico aplicado na reabilitação de atletas. In:X Encontro Latino Americano de Iniciação Científica. Anais..:UNIVAP; 2006: 2554-2557. Disponível em http://www.inicepg.univap.br/cd/INIC_2006/epg/03/ EPG00000131.ok.pdf.

15- Utsch RS, Guerra TC, Porcaro CA. Influência do treinamento pliométrico em areia e grama sobre a potência e velocidade em jogadores de futebol juvenis. Revista Digital EFDeportes - Buenos Aires - 2009;14(137). Disponível em: http://www.efdeportes.com/efd137/treinamento-pliometrico-em-areia-e-grama-em-futebol.htm.
16- Boff R e Da Silva ER. Aplicabilidade do treinamento pliométrico para jogadores de voleibol. Revista Digital EFDeportes - Buenos Aires- 2009;14(138). Disponível em http://www.efdeportes.com/efd138/treinamento-pliometrico-para-jogadores-de voleibol.htm.

17- Cosio-Lima LM, Reynolds KL, Winter C. Effects of physioball and conventional floor exercises on early phase adaptations in back and abdominal core stability and balance in women. J. Strength Conditioning Research, 2003;17(4):721-25. Disponível em: http://www.portalsaudebrasil.com/artigospsb/treinofunc6.pdf.

18- Michell TB, Ross SE, Blackburn JT et al. Functional balance training, with or without exercise sandals, for subjects with stable or unstable ankles. J. Athletic Training. 2006; 41(4):393-98. Disponível em: http://www.portalsaudebrasil.com/artigospsb/treinofunc16.pdf.

19- Corrêa LB, Oliveira RN, Cantareli, FC, Cunha LS. Efeito do treinamento muscular periférico na capacidade funcional e qualidade de vida nos pacientes em hemodiálise. J. Bras. Nefrol. 2009;31(1):18-24.

20- Thompson CJ, Cobb KM, Blackwell J. Functional training improves club head speed and functional fitness in older golfers. J. Strength Conditioning Research, 2007;21(1):131-37. Disponível em: http://www.portalsaudebrasil.com/ artigospsb/treinofunc34.pdf.

21- Oliveira MHS, Didone $\mathrm{CH}$, Dutra $\mathrm{PH}$ et al. O treinamento funcional na reeducação da capacidade funcional após reconstrução de ligamento cruzado anterior (LCA). In: II Congresso de Ciência do Desporto \& I Simpósio Internacional de Ciência do Desporto. Anais... São Paulo. CESET/UNICAMP. 2007. Disponível em: http://www.fef. unicamp.br/eventos/ccd2/trabalhos/33972434839.pdf.

22- Leal SMO, Borges EGS, Fonseca MA et al. Efeitos do treinamento funcional na autonomia funcional, equilíbrio e qualidade de vida de idosas. Rev Bras de $\mathrm{Ci}$ e Mov, 2009;17(3):61-69. Disponível em: http://portalrevistas.ucb.br/index.php/RBCM/article/viewFile/1045/1401.

23- King MB, Judge JO, Whipple R, Wolfson L. Reliability and responsiveness of two physical performance measures examined in the context of a functional training intervention. Physical Therapy. 2000 80(1):8-16, 2000. Disponível em: http://www.portalsaudebrasil.com/artigospsb/treinofunc11.pdf. 
24- Yaggie JA, Campbell BM. Effects of balance training on selected skills. J. Strength Conditioning Research, 2006;20(2):422-28. Disponível em: http://www.alexandrelevangelista.com.br/wp-content/uploads/2010/02/ balance-trainiing1.pdf.

25- Myer GD, Ford KR, Brent JL et al. The effects of plyometric vs. Dynamic stabilization and balance training on power, balance, and landing force in female athletes. J. Strength Conditioning Research, 2006;20(2):345-353. Disponível em: http://www.alexandrelevangelista.com. br/wp-content/uploads/2010/02/pliome-tria-x-balancetraining1.pdf.

26- Paw MJMP, Poppel MNM, Twisk JWR, Mechelen WV. Effects of resistance and all-round, functional training on quality of life, vitality and depression of older adults living in long-term care facilities: a 'randomized' controlled trial. BMC Geriatrics. 2004, 4(9). doi:10.1186/1471-2318-4-5.
27- Spennewyn KC. Strength outcomes in fixed versus free-form resistance equipment. J. Strength Conditioning Research, 2008;22(1)75-81. Disponível em: http://www. portalsaudebrasil.com/artigospsb/treinofunc31.pdf.

28- Braz TV, Spigolon LMP, Borin JP. Caracterização dos meios e métodos de influência prática no treinamento em futebolistas profissionais. Rev Bras Ciênc Esporte [online]. 2012;34(2):495-511.

\section{ENDEREÇO PARA CORRESPONDÊNCIA:}

Cláudio Joaquim Borba-Pinheiro

(claudioborba18@gmail.com)

Endereço: Universidade do Estado do Pará (UEPA) Campus XIII de Tucuruí.

Rua 4, n²0 - Bairro: Santa Mônica - CEP:68458-100. Tucuruí, PA - Brasil. 